\title{
Computerized planimetry evaluation of hyperbaric oxygen therapy in the treatment of diabetic foot
}

\author{
Marek Kawecki', 2, A, B, D, E, Jarosław Pasek ${ }^{3,4, A, C-E}$, Grzegorz Cieślar3, 4, D-F , Aleksander Sieroń3 A, B, E, F, \\ Grzegorz Knefel ${ }^{1, C, E, F}$, Mariusz Nowak ${ }^{4, C, F}$, Justyna Glik ${ }^{1,6, C, E, F}$ \\ ${ }^{1}$ Centre for Burns Treatment, Siemianowice Śląskie, Poland \\ ${ }^{2}$ Department of Health Sciences, Technical-Humanistic Academy, Bielsko-Biała Poland \\ ${ }^{3}$ Department of Internal Medicine, Angiology and Physical Medicine, School of Medicine with the Division of Dentistry in Zabrze, Medical University of Silesia in Katowice, Poland \\ ${ }^{4}$ Academy of Jan Długosz in Częstochowa, Institute of Physical Education Tourism and Physiotherapy, Częstochowa, Poland \\ ${ }^{5}$ Department of Chronic Wound Treatment Organization of the School of Health Sciences, Medical University of Silesia, Katowice, Poland \\ A - research concept and design; $\mathrm{B}$ - collection and/or assembly of data; $\mathrm{C}$ - data analysis and interpretation; \\ $D$ - writing the article; $E$ - critical revision of the article; $F$ - final approval of the article
}

Address for correspondence

Jarosław Pasek

E-mail:jarus_tomus@02.pl

\section{Funding sources}

None declared

\section{Conflict of interest}

None declared

Received on May 29, 2016

Reviewed on September 29, 2016

Accepted on October 26, 2016

\begin{abstract}
Background. Diabetic foot ulcer is one of the major complications of diabetes mellitus in adults.

Objectives. The aim of the study was to conduct a planimetry evaluation of the effectiveness of hyperbaric oxygen therapy (HBOT) in the treatment of patients with vascular disorders caused by diabetic foot.

Material and methods. The study included 94 patients, 30 females (32\%) and 64 males (68\%), aged 33-76 years, with diabetes lasting 1.5-32 years, who underwent HBOT due to diabetic foot. All patients from that group underwent vascular procedures prior to HBOT. In qualifying patients for hyperbaric oxygen therapy, transcutaneous oximetry method was applied (30-60 exposures in hyperbaric oxygen at pressure of 2.5 ATA). Progress in wound healing was evaluated by computerized planimetry system IRIS 4.

Results. In 26 patients the wounds were completely closed and in 37 patients the topical state was significantly improved - the wound surface decreased by 34\% in average. During the treatment, in 11 patients amputation of fingers and metatarsal necrotic bones was performed, while in 9 patients amputation was prevented.
\end{abstract}

Conclusions. A planimetry evaluation showed that the application of HBOT in the treatment of diabetic foot enhances foot ulcer healing, reduces tissue damage, contributes to the reduction of complications related to soft tissue and bone infections.

Key words: diabetic foot, hyperbaric oxygen therapy, computerized planimetry

DOI

$10.17219 /$ acem $/ 66392$

Copyright

Copyright by Author(s)

This is an article distributed under the terms of the

Creative Commons Attribution Non-Commercial License

(http://creativecommons.org/licenses/by-nc-nd/4.0/) 


\section{Introduction}

According to estimated values, diabetes mellitus affects $5 \%$ of the world's population, and the number is systematically growing. The estimated number of diabetic patients in Poland ranges between 1.5 and 2 million. ${ }^{1}$ One of the most serious complications of diabetes is diabetic foot. Diabetic foot is a complex of acute and persistent symptoms occurring in patients suffering from long-lasting not compensated diabetes mellitus, related to damages in foot vascular and nervous system, as well as a tendency to delayed wound healing, infection or gangrene of the foot. Two main risk factors that cause diabetic foot ulcer are diabetic neuropathy and micro as well as macroangiopathy. ${ }^{2}$

Diabetic foot ulcer is one of the major complications of diabetes mellitus. It occurs in $15 \%$ of all patients with diabetes and precedes $84 \%$ of all lower leg amputations. ${ }^{3}$ The probability of lower extremity amputation in diabetic patients is approximately 25 times higher than in patients with a vascular risk. Every 5 out of 6 amputations due to the lower extremity vascular dysfunction is performed in diabetic patients. ${ }^{4}$

Complications connected with diabetic foot, such as difficulties in healing wounds, or non-healing ulcers, wet and dry gangrene of soft tissue as well as foot osteitis, could lead to the necessity of amputating fingers, metatarsal necrotic bones or even the whole foot. ${ }^{4,5}$ Nowadays, the combined treatment of diabetic foot is recommended including conservative treatment, revascularization of lesion area (stents, bypasses), surgical treatment including wound debridement (necrotic tissue demarcation, soft tissue incision, purulence cistern drainage, often resections within foot skeletal system, and amputations as well), empiric antibiotic therapy, and subsequently targeted therapy and hyperbaric oxygen therapy (HBOT). Hyperbaric oxygen therapy was defined as a medication by Gottlieb in $1977 .^{6}$ Diabetic foot syndrome is accepted as an indication for therapy in hyperbaric chamber by European Committee of Hyperbaric Medicine (ECHM) and Undersea and Hyperbaric Medical Society (UHMS) as well.,

\section{Material and methods}

The study comprised a group of 94 patients with vascular disorders caused by the diabetic foot ulcers, among them 30 female (32\%) and 64 (68\%) male, in the age between 33 and 76 years (mean age 42 years) who underwent HBOT at the Oxygen Therapy Ward of the Center for Burns Treatment in Siemianowice Śląskie between June 2012 and December 2015. Diabetes mellitus history of patients reported in medical records was between 1.5 and 32 years before starting hyperbaric oxygen therapy.

Depending on the pathogenic background of diabetic foot syndrome, the patients were divided into 2 groups: ischemic diabetic foot syndrome (50 patients) and neurogenic diabetic foot syndrome (44 patients), without any significant differences between them regarding sex and age of the patients, as well as the time of diabetes mellitus history.

In 9 patients with ischemic diabetic foot syndrome $(9.6 \%$ of the whole group), blood flow disturbances of significant grade in lower extremity arteries with the symptoms of peripheral ischemia, diagnosed by Doppler ultrasonography and angio-CT, were observed. They were caused by advanced atherosclerosis. Among those patients, 5 (5.3\% of the whole group) were subjected to vascular procedures (bypass -2 and stent -3 ) prior to HBO therapy.

\section{Oxygen hyperbaric therapy procedure}

After qualification basing on transcutaneous oxymetry examination, HBOT was carried out in a multiplace hyperbaric chamber once a day, 5 times a week. The treatment protocol consisted of $60 \mathrm{~min}$ lasting periods of inhalation of $100 \%$ oxygen at a pressure of 2.5 ATA, interspersed with 2 "air breaks" lasting $5 \mathrm{~min}$, after each $30 \mathrm{~min}$ of inhalation. A cycle of HBOT consisted of 30 to 60 procedures, depending on the healing results.

\section{Evaluation of healing process}

The course of healing was evaluated by computerized planimetry (IRIS-4 system, manufactured by Medi.Com, Wrocław, Poland). This method is based on the wound's digital picture evaluation with a determination of the parameters listed below: wound perimeter $(\mathrm{O})$, wound surface (S), distance between maximally outlaying points on wound edge (d), wound circularity (near-circle level of wound shape with values $0-1$, where 1 means circle) (C). Pictures of the wound were taken every 5 to 7 days of therapy. From 3 to 7 measurements (mean 4) were performed for 1 patient.

\section{Statistical analysis}

Statistical analysis has been performed with the use of STATISTICA v. 6.0 software (StatSoft Inc., Tulsa, USA). $A X^{2}$ test has been used to determine the significance of differences of non-parametric variables in both groups, while for the analysis of differences between the values of ulcer surface before and after treatment in each group, as well as between both groups, an analysis of variance with the subsequent Mann Whitney $U$ test has been carried out. In all analyses, the significance level was set at $\mathrm{p}<0.05$.

\section{Results}

The results of HBOT of skin ulcer in patients from both groups are presented in Table 1 . As a result of the treatment, ulcer healing was completed without any amputations in 26 (27.7\%) patients (14 patients with ischemic foot 
syndrome and 12 with neurogenic foot syndrome). Topical status of wound was significantly improved (wound was cleaned out from necrotic tissue and decontaminated) in 37 (39.4\%) patients (20 patients with ischemic foot syndrome and 17 with neurogenic foot syndrome) who completed the whole cycle of the HBOT. In the group of patients with topical status improvement, a planimetric examination demonstrated a decrease of wound surface by $34 \%$ on average, compared with the results of initial planimetric examination before the beginning of HBOT. A total of 10 patients (10.6\%) (5 patients with ischemic foot syndrome and 5 with neurogenic foot syndrome) discontinued HBOT after 1 to 19 exposures due to the deterioration of health status (laryngological complications -6 patients, exacerbation of chronic circulatory insufficiency symptoms - 3 patients, claustrophobia - 1 patient), while $5(5.3 \%)$ patients (2 patients with ischemic foot syndrome and 3 with neurogenic foot syndrome) discontinued therapy arbitrarily, without giving any reason. In those patients, a planimetric examination showed an improvement of topical status, resulting in a decrease of ulcer surface by $5 \%$ to $32 \%$ (mean $17.7 \%$ ). In 14 (14.9\%) patients (8 patients with ischemic foot syndrome and 6 with neurogenic foot syndrome) no topical improvement of ulcer surface was observed. In $2(2.1 \%)$ patients (1 patient with ischemic foot syndrome and 1 with neurogenic foot syndrome) the topical status of the wound became exacerbated - the ulcer surface increased by $9 \%$ on average, compared with the results of planimetric examination before the beginning of HBOT. The statistical analysis performed with use of $\chi^{2}$ test confirmed that the results of treatment in both groups did not differ significantly $\left(X^{2}=0.197, X_{\alpha}^{2}=7.815 ; \mathrm{p}>0.05\right)$.

In $11(11.6 \%)$ patients (7 patients with ischemic foot syndrome and 4 with neurogenic foot syndrome) due to the lack of healing during HBOT cycle, amputations were performed of fingers and metatarsal necrotic bones,

Table 1. Therapeutic effect of HBOT in patients with skin ulcer in the course of both types of diabetic foot syndrome

\begin{tabular}{|l|c|c|c|c|c|}
$\begin{array}{l}\text { Type of diabetic } \\
\text { foot syndrome }\end{array}$ & $\begin{array}{c}\text { Complete } \\
\text { healing }\end{array}$ & $\begin{array}{c}\text { Partial } \\
\text { healing }\end{array}$ & No effect & $\begin{array}{c}\text { Topical } \\
\text { exacerbation }\end{array}$ & Total \\
\hline Ischemic & 14 & 27 & 8 & 1 & 50 \\
\hline Neurogenic & 12 & 25 & 6 & 1 & 44 \\
\hline Total & 26 & 52 & 14 & 2 & 94 \\
\hline
\end{tabular}

Table 2. Comparison of the average ulcer surface (mean value \pm SD) before and after HBOT in patients with ischemic and neurogenic foot syndrome, with statistical analysis

\begin{tabular}{|l|c|c|c|}
$\begin{array}{c}\text { Type of diabetic foot } \\
\text { syndrome }\end{array}$ & $\begin{array}{c}\text { Ulcer surface before } \\
\text { HBOT }\left[\mathrm{mm}^{2}\right]\end{array}$ & $\begin{array}{c}\text { Ulcer surface after } \\
\text { HBOT }\left[\mathrm{mm}^{2}\right]\end{array}$ & $p$-value \\
\hline Ischemic & $522.4 \pm 108.7$ & $285.8 \pm 90.4$ & ${ }^{*} \mathrm{p}<0.001$ \\
\hline Neurogenic & $509.3 \pm 99.6$ & $296.2 \pm 82.8$ & ${ }^{*} \mathrm{p}<0.001$ \\
\hline Statistical significance & $\# \mathrm{p}=0.540$ & $\# \mathrm{p}=0.562$ & \\
\hline
\end{tabular}

* before and after treatment in particular groups; ${ }^{*}$ comparison between both groups. while in $9(9.6 \%)$ patients (6 patients with ischemic foot syndrome and 3 with neurogenic foot syndrome) amputations which were initially planned at the beginning of the treatment were prevented by hyperbaric oxygen therapy.

The final comparison of the average ulcer surface (mean value \pm SD) before and after HBOT in patients with ischemic and neurogenic foot syndrome is presented in Table 2. The statistical analysis confirmed a significant decrease in the average ulcer surface after HBOT both in patients with ischemic foot syndrome $(\mathrm{p}=0.004)$ and in patients with neurogenic diabetic foot syndrome $(\mathrm{p}<0.05)$. The average relative changes in ulcer surface values observed after the end of HBOT in both groups (45.3\% in ischemic type and $41.8 \%$ in neurogenic type of diabetic foot syndrome, respectively) did not differ significantly ( $p>0.05$ ).

The obtained results proved that HBOT is an efficient method of treatment of topical lesions in both types of diabetic foot syndrome.

In Fig. 1-4, examples of topical status improvement estimated by computerized planimetry of ulcer dimensions in 3 patients with a diabetic foot ulcer exposed to combined treatment, including HBOT were presented.

\section{Discussion}

The results of the present study confirm findings reported in previous randomized, both double-blind and unblinded trials that HBOT enhances foot ulcer healing in patients with a diabetic foot. ${ }^{9-12}$ Our healing rate following HBOT estimated immediately after completing hyperbaric oxygen cycle is in agreement with the aforementioned studies.

The incidence of previous vascular intervention at the time of randomization in our patients (9.6\%) was much lower than in studies conducted by other authors: $38 \%$ and $>50 \%$, and this could explain the better results in long-term follow up obtained in those trials. ${ }^{12,13}$

Our findings are in agreement with some studies which have shown the beneficial effect of HBOT in preventing amputations. ${ }^{10,11,13}$

Due to Henry's law, the application of hyperbaric oxygen therapy causes a 15-fold increase in oxygen pressure in blood plasma (under therapeutic pressure of 2.5 ATA) with concomitant $100 \%$ oxygen saturation of hemoglobin. Therefore, during $\mathrm{HBO}$ compared to normobaric conditions, $\mathrm{pO}_{2}$ gradient between the wound's edge and the center increases significantly.

Computerized planimetry enables an objective assessment of the healing process of wounds, based on the evaluation of wound surface, 


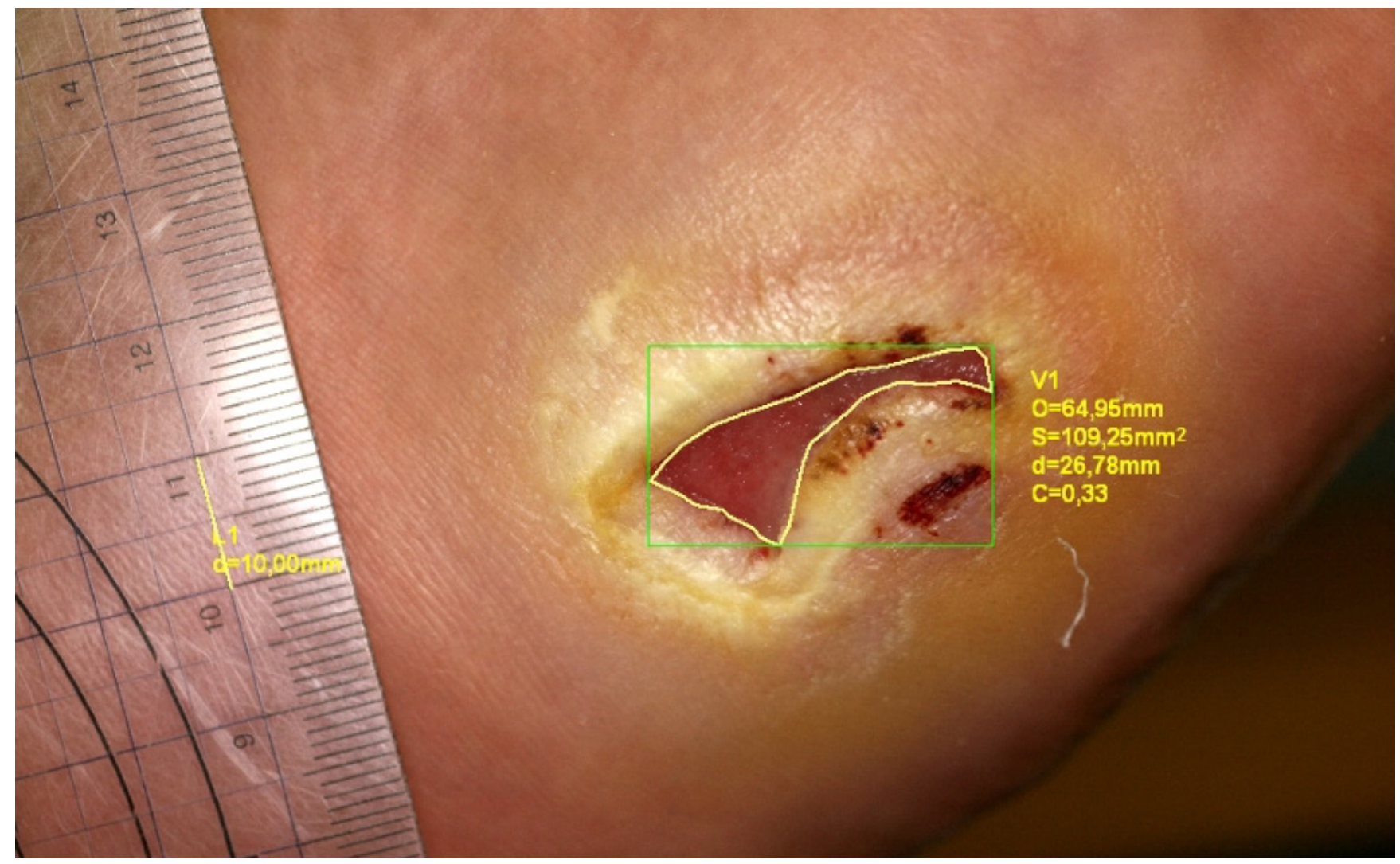

Fig. 1. Patient with diabetic foot ulcer (6 months) - the topical state before the beginning of combined treatment including HBOT with evaluation of wound dimensions by means of computerized planimetry; $\mathrm{O}$ - wound perimeter; $\mathrm{S}$ - wound surface; $\mathrm{d}$ - distance between maximally outlaying points on wound edge; C - wound circularity (near-circle level of wound shape with values $0-1$, where 1 means circle)

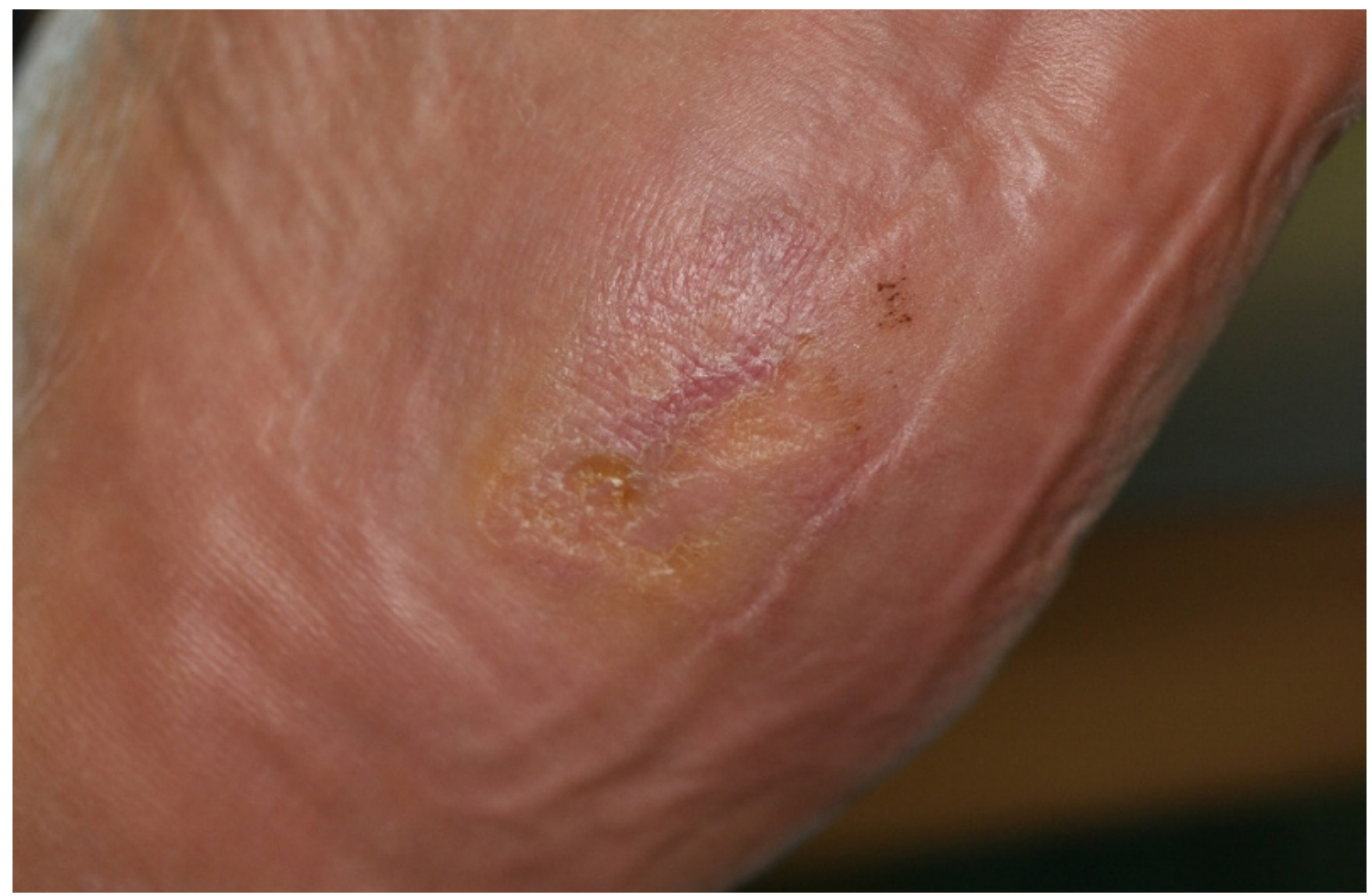

Fig. 2. The topical state after 36 procedures of combined treatment including HBOT - visible complete healing of the wound 


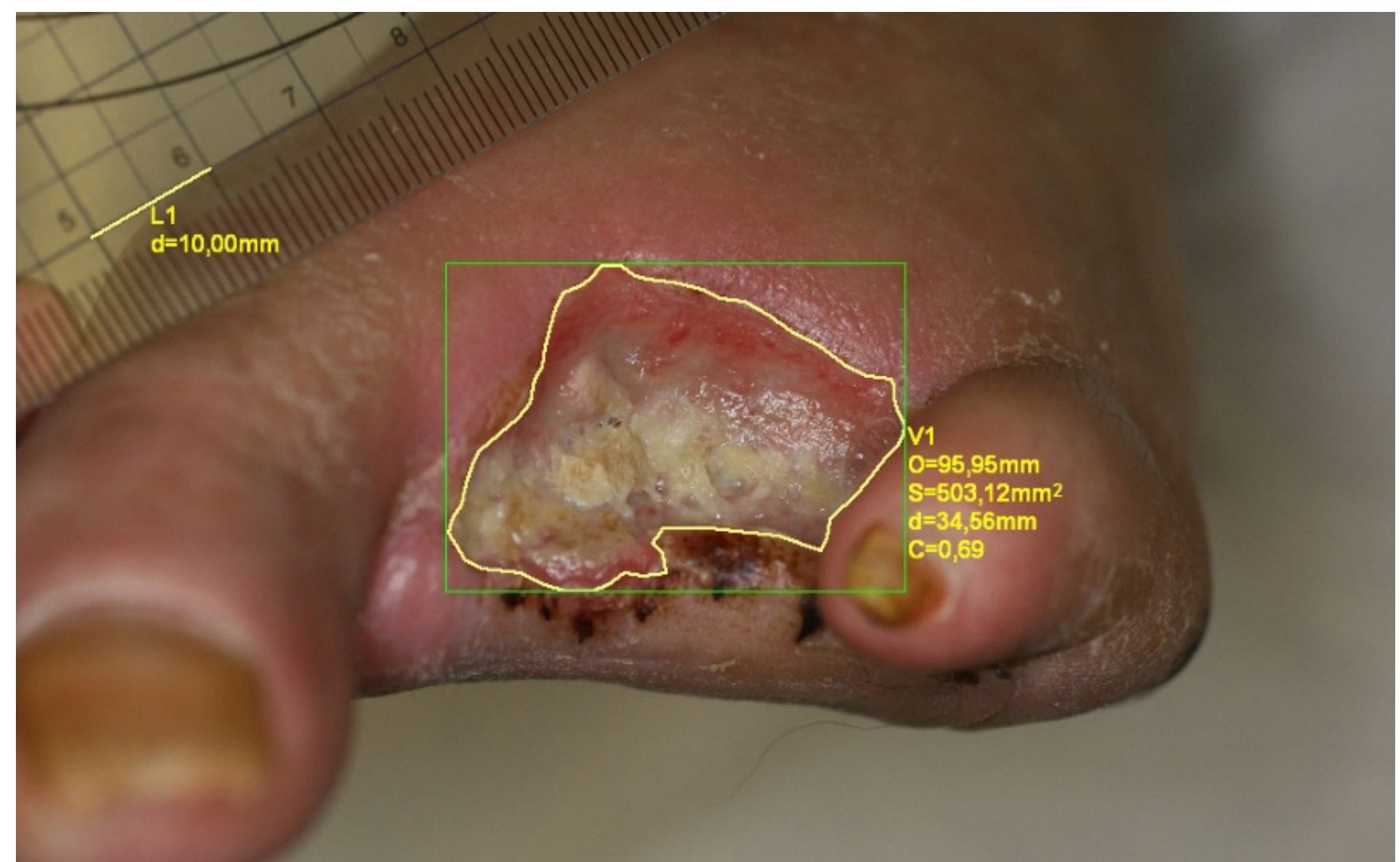

Fig. 3. Patient with diabetic foot ulcer (2 years) after amputation of right foot fingers II-IV - the topical state before the beginning of combined treatment including HBOT with evaluation wound dimensions by means of computerized planimetry; $\mathrm{O}$ - wound perimeter; $\mathrm{S}$ - wound surface; $\mathrm{d}$ - distance between maximally outlaying points on wound edge; C - wound circularity (near-circle level of wound shape with values $0-1$, where 1 means circle)

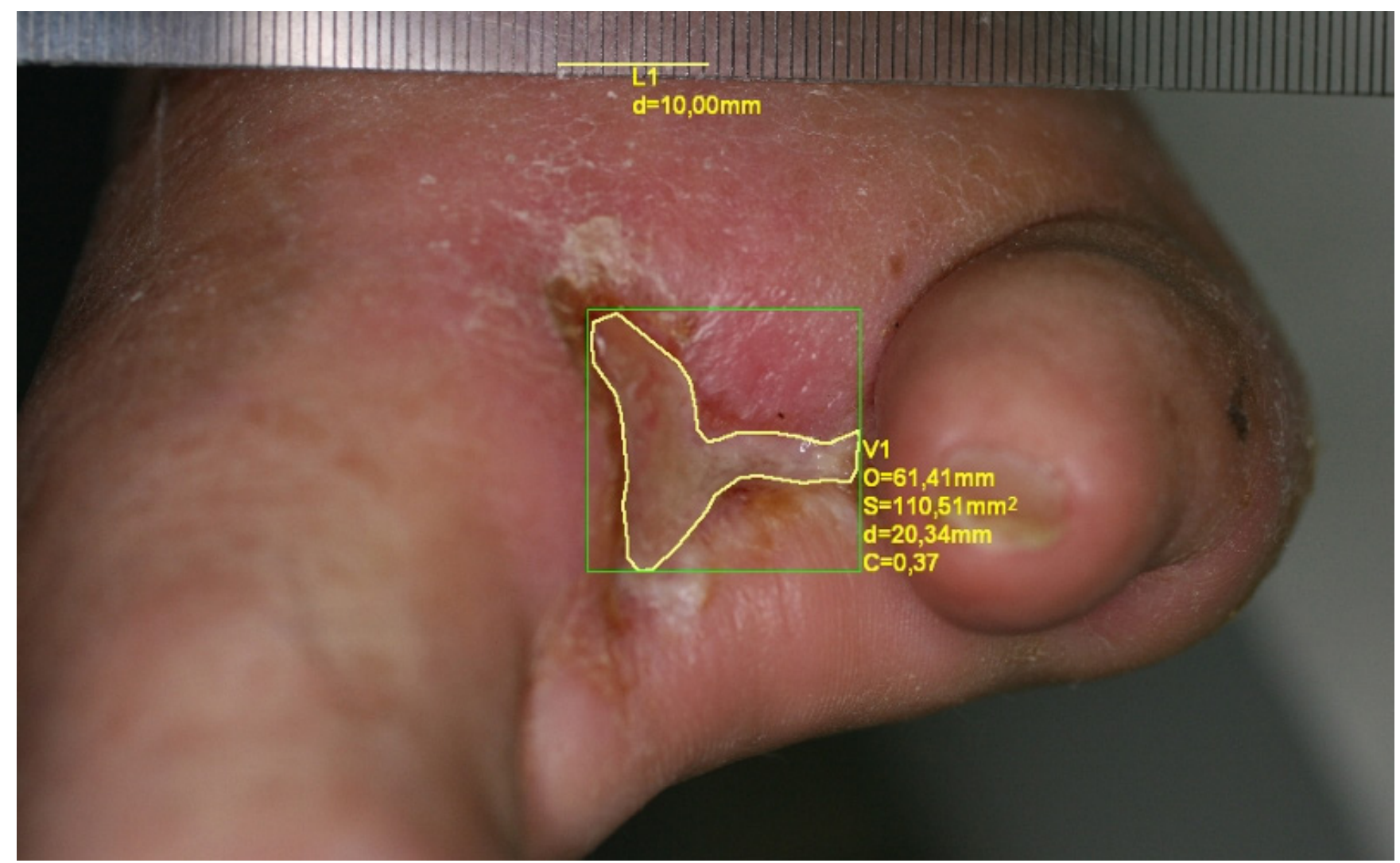

Fig. 4. The topical state after 45 procedures of combined treatment including HBOT with evaluation wound dimensions by means of computerized planimetry; $\mathrm{O}$ - wound perimeter; $\mathrm{S}$ - wound surface; $\mathrm{d}$ - distance between maximally outlaying points on wound edge; $\mathrm{C}$ - wound circularity (near-circle level of wound shape with values $0-1$, where 1 means circle); visible distinct decrease of wound dimensions 
wound periphery and changes of wound size (percentage of surface compared with previous measurement). ${ }^{14} \mathrm{Pla}$ nimetry is based on precise contouring of wound edges, using its digital image.

Monoplanar wounds of diabetic foot patients were covered by the measurement system IRIS-4. Ring-shape and multiplanar wounds cannot be objectively evaluated by this method. Wound photographing and evaluation by IRIS 4 program enabled us to determine the precise dimension and surface of tissue defects. The implementation of cyclic, timed documentation using high resolution digital imaging and data formulating in the IRIS system, demonstrated a gradual decrease of its surface, even in a small range, and objectified our clinical observation, allowing us to evaluate even discrete lesions in a wound.

Introducing a complex treatment of diabetic foot ulcer into clinical practice, combined with hyperbaric oxygen, offers an opportunity for a quick recovery and an active life, and reduces a budget load due to long-term therapy. ${ }^{15}$ But one must remember that oxygen hyperbaric therapy cannot be considered as treatment of choice, as it is only an adjuvant method for basic conventional therapy of diabetic foot patients.

\section{Conclusions}

The application of HBOT in the treatment of diabetic foot enhances foot ulcer healing confirmed by computerized planimetry evaluation, both in the case of ischemic and neurogenic type of diabetic foot syndrome, it reduces tissue damage, contributes to the reduction of complications related to soft tissue and bone infections, and therefore enables idiopathic closure of wound.

\section{References}

1. Wu SC, Driver VR, Wrobel JS, Armstrong DG. Foot ulcers in the diabetic patient, prevention and treatment. Vasc Health Risk Manag. 2007;3:65-76.

2. Brem H, Tomic-Canic M. Cellular and molecular basis of wound healing in diabetes. J Clin Invest. 2007;117:1219-1222.

3. Pecoraro RE, Reiber EM, Burgess EM. Pathways to diabetic limb amputation. Basis for prevention. Diabetes Care. 1990;13:513-521.

4. Rudzki J, Sadliński C, Ginko T, et al. Problem of treating of the socalled diabetic foot. Wiad Lek. 1985;38:417-420.

5. Armstrong DG, Lavery LA, Harkles LB. Validation of a diabetic wound classification system: The contribution of depth, infection, and ischemia to risk of amputation. Diabetes Care. 1998;21:855-859.

6. Gottlieb SF. Oxygen under pressure and microorganisms, In: Davis JC, Hunt TK, eds. Hyperbaric oxygen therapy. Bethesda: Undersea Medical Society Inc.; 1986:79-99.

7. Hamilton Farrell MR. Fourth Consensus Conference of the European Committee on Hyperbaric Medicine, London. December 4-5 1998. Hyperbaric oxygen in the management of foot lesions in diabetic patients. Diabetes Nutr Metab. 1999;12:47-48.

8. Wattel F, Mathieu D. Methodology for assessing hyperbaric oxygen therapy in clinical practice. In: Mathieu D, ed. Handbook on hyperbaric medicine. Dodrecht: Springer; 2006:163-170.

9. Abidia A, Laden G, Kuhan G, et al. The role of hyperbaric oxygen therapy in ischemic diabetic lower extremity ulcers: A double-blind randomized-controlled trial. Eur J Vasc Endovasc Surg. 2003;25:513-518.

10. Duzgun AP, Satir HZ, Ozozan O, Saylam B, Kulah B, Coskun F. Effect of hyperbaric oxygen therapy on healing of diabetic foot ulcers. J Foot Ankle Surg. 2008;47:515-519.

11. Kalani M, Jörneskog G, Naderi N, Lind F, Brismar K. Hyperbaric oxygen (HBO) therapy in treatment of diabetic foot ulcers: Long-term follow-up. J Diabetes Complications. 2002;16:153-158.

12. Löndahl M, Katzman P, Nilsson A, Hammarlund C. Hyperbaric oxygen therapy facilitates healing of chronic foot ulcers in patients with diabetes. Diabetes Care. 2010;33:998-1003.

13. Kessler L, Bilbault P, Ortéga F, et al. Hyperbaric oxygenation accelerates the healing rate of non- ischemic chronic diabetic foot ulcers: A prospective randomized study. Diabetes Care. 2003;26:2378-2382.

14. Mayrovitz HN, Soontupe LB. Wound areas by computerized planimetry of digital images: Accuracy and reliability. Adv Skin Wound Care. 2009;22:222-229.

15. Cianci $P$, Hunt TK. Long term results of aggressive management of diabetic foot ulcers suggest significant cost effectiveness. Wound Repair Regen. 1997;5:141-146. 